\title{
Nutrients and Cancer: An Introduction to Cesium Therapy
}

\author{
H. E. SARTORI, M.D. \\ Life Science Universal Medical Center, Suite 306 \\ 4501 Connecticut Avenue, Washington, DC 20008
}

\begin{abstract}
SARTORI. H. E. N Nutrients and Cancer: An Introduction to Cesium Therapy. PH ARM ACOL BIOCHEM B EH AV 21: Suppl 1: 7-10. 1984.A brief overview on the relevance of dietary factors in both development and prevention of cancer is presented. The pharmacologic properties of various food ingredients are discussed. Establishing of a special diet for the cancer patient is suggested. In addition, avoidance of certain foods is recommended to counteract mucus production of cancer cells. Evaluation of the nutrient content of certain diets in regions with low incidence of cancer has advanced the use of certain alkali metals, i.e., rubidium and cesium, as chemotherapeutic agents. The rationale for this approach, termed the "high pH " therapy, resides in changing the acidic $\mathrm{pH}$ range of the cancer cell by cesium (or rubidium) towards weak alkalinity in which the survival of the cancer cell is endangered, and the formation of acidic and toxic materials, normally formed in cancer cells, is neutralized and eliminated.
\end{abstract}

$\begin{array}{llllll}\text { Antioxidants } & \text { Cesium } & \text { Diet } & \text { Essential fatty acids } & \text { Fish liver oils } & \text { Germanium } \\ \text { Minerals } & \text { Oxygenation } & \text { Ozone } & \text { Potassium } & \text { Rubidium } & \text { Sodium }\end{array}$

ONE to 1.3 million cases of new cancer are anticipated in USA for the year 1984. Cancer mortality is second only to cardiovascular disease as the most common cause of death in the USA and in most European countries. Squamous and basal cell skin cancer may contribute about 400,000 new cases, while lung and colorectal cancer may account for 139.000 cases each, compared to 116,000 for breast cancer of which 1.000 is projected for men. The remainder of cancers anticipated this year, in descending order of frequency, includes prostate, uterus, urinary, oral, pancreas, leukemias, ovary, and skin melanoma. The mortality of cancer is estimated for this year at approximately 185 cases per 100.000 of population or a total of 450,000 . This is compared to $440.000,431.000$, and 423,000 deaths from cancers that have been reported for 1983, 1982 and 1981, respectively [ for 1984: 535,000; for 2004 (expected): 567,000].

Treatment modalities of cancer include surgery, radiation and chemotherapy. In those cases where surgery was successful the body's own immune system was able to counteract the reduced amount of tumor tissue. Surgery is likely to produce metastasis without stimulation of the immune system. Radiation may cause damages to the organism, e.g., cancerogenicity of $x$-rays and other radiations, and their depression of the immune system is well known. Prolonged chemotherapy may cause severe to lethal side effect in some instances, and the use of hormones and interferon are useful only for very few cases of cancer. Conventional treatments of cancer have produced 5year survival rates which do not reflect the inexorable gradual deterioration of the cancer patients, nor their suffering from various treatment-related adverse reactions, and where chemotherapy of, e.g. breast cancer may shorten the life by 18 to 36 months v. no treatments at all. [See A ppendix II: Summary of A dverse Effects]

Alternate cancer therapies include Orthomolecular/Eumetabolic approaches and Priore-radiation of cancer. The latter technique has been developed by A ntoine Priore in France and has been described in detail elsewhere [3]. In brief, it generates a combination of radiations in rotating plasmic solutions that are capable of penetrating living tissues for therapeutic purposes, without destroying biological systems. The innovative techniques employed in the device since the early 1960 's have attracted scientific attention and research in the years following its introduction has demonstrated its efficacy in animal experiments, i.e., cure of cancer-bearing rats, attenuation of hypercholesterolemia in rabbits and survival of mice injected with fatal doses of Trypanosoma equiperdum, compared to corresponding controls. This approach is directed primarily towards a stimulation of the immune system rather than the cancerous cells themselves, resulting presumably in an acquired immunity which becomes intense and is even transferable by blood transfusion.

Dietary requirements which may lead to cancer have been generally ignored. Various diets and eating habits appear to bear some significance to susceptibility as well as to prevention and/or treatment of cancer. The macrobiotic-related dietary approach of M ichio Kushi $[4,5]$ for cancer treatment focuses on the use of whole grains, e.g., $50 \%$ to $60 \%$ of daily intake, with locally grown vegetables, e.g., $20 \%$ to $30 \%$, excluding potatoes, tomatoes, peppers, eggplant, and especially tropical fruits. This is complemented by $10 \%$ to $15 \%$ of daily food consumption of beans and seaweeds in addition to $5 \%$ miso soup ( $\&$ other soybean products) and about $5 \%$ supplemental foods. The main difficulty with this approach is the necessity of complete compliance. The possible association of specific diet ingredients to cancer development, treatment and/or prevention is outlined below which then leads to the rationale of the use of an alkali metal, i.e., cesium, as chemotherapeutic agent.

\section{NUTRITION AND CANCER MUCUS}

The cancer cell is known to produce large amounts of mucus and this, in turn, shields the cancer cells from the immune system and from being penetrated by chemotherapeutic agents. It even protects against radiation if the layer of mucus is thickened up. Later this mucus can also be demonstrated in the blood, e.g., with the HLB blood test. U se of certain agents help to dissolve the blocking effect of the mucus. This includes the use of beta-carotene which decomposes blocking mucoid proteins mediated by el ectrical charges. It gets inactivated and decolorized by the blocking mucoid. The necessary dosage for optimal effect produces the so-called "carotenemia", an orange-yellow tinge to the patient's skin. Likewise, heparin inactivates the immune repelling and immune binding capacities of the mucoid proteins by electrical charges. Furthermore, compounds like bromelain, papain (in green papayas), Wobemugos ${ }^{\circledR}$, or pancreatic enzymes will not only break down mucus but also destroy leukemic cells. 
TABLE I

CANCER PROTECTIVE NUTRIENTS WHICH MAY REDUCE INCIDENCE OF CANCER

Substance/Compound*

Cesium and Rubidium

Omega-3 Essential Fatty A cids

(Eicosapentaenoic acid and

Docosahexaenoic acid)

Carotene and V itamin A

Selenium

Vitamin C and Bioflavonoids

Germanium

Vitamin D2 (Ergocal ciferol)

Molybdenum

Zink

M agnesium

N itriles(amygdalin; mandel onitrile-• glucuronide or Laetrile $\AA)^{2}$

Allicin and sinigrin

Taurine

Squalene

Saponins

Photonic Energy

Niacinamide

Food Fiber

B-complex vitamins, especially Riboflavin (Vitamin B 2)

Vitamin E (mixed D-Tocopherols)

Pantothenic acid

Folic A cid

Certain A mino A cids (Cystein, A rginine, Ornithine; also IGF 1, etc., from Cornu parvum of the Chinese deer Cervus nippon/elaphus)
Possible Mechanism of Action

Raise $\mathbf{p H}$ in cancer cells and gene repair.

Repair cell membranes; enhance the immune system and prostaglandin synthesis.

Decompose blocking mucus and enhance immune system.

A ntioxidant and broadens electron donor capacity of cancer cell membrane.

Enhance the immune system.

Oxygen carrier; interferon stimulator, and gene repair.

Immune enhancer; precursor of tumosteron.

M embrane stabilizer; part of xanthine oxidase which mobilizes iron from liver and of aldehyde oxidase necessary for fat oxidation.

Electron donor; antioxidant, and immune stimulant.

Enzyme activator; gene and membrane stabilizer.

$B$ roaden el ectron donor capacity of the cancer cell membrane; release of cancer growth inhibiting benzaldehyde and cyanide.

$N$ atural cancer inhibitors.

Desalting substance that lowers sodium in cancer cells.

Precursor of dehydroepiandrosterone (DHEA) an anticancer, antiaging, and antiobesity factor.

M embrane and gene stabilizing.

Decomposes blocking mucus surrounding the cancer cells (are found in KIRLIAN positive raw vegetables and fresh vegetable juices, especially carrot juice.)

Slows down mitosis and the multiplication of cancer cells.

Reduces passage-time, decreasing the exposure of intestines, especially the colon, to carcinogens; binds toxic substances and carcinogens.

Required for cell respiration (esp. B 2) and catal ysts for numerous enzymes.

A ntioxidant; membrane and gene stabilizer.

Stimulates adrenals and DHEA-formation.

Coenzyme with B 12 and C for protein utilization; carbon carrier for heme and nucleic acid formation: thus it normalizes gene formation of cancers. It al so stimulates the production of hydrochloric acid.

Stimulate the anticancer human growth hormone

*See text for the presence of these compounds in various food ingredients.

Notes: ${ }^{1}$ Rubidium is especially beneficial for pancreatic and liver cancers and other malignancies that present with clinical depression. Rubidium chloride $(\mathrm{RbCl})$ is established as an antidepressant of low toxicity and acts similar to the equally nontoxic lithium orotate.

It is recommended, therefore, to avoid all mucus producing foods, e.g., all dairy products, except goat milk derivatives, egg whites (whereas soft yolks are highly beneficial) for all blood types (with possible exception of Type Bs), and, more specifically, all grains, except brown rice, for Type Os (and Bs), all meat, especially for Type As (and Abs) which do well on whole grains and locally grown vegetables, all soy bean (Glycine max) derivatives for Type Os and Bs (e.g., soy milk, tofu, tempe, etc.), tomatoes, except for Type Os, most beans and nuts, except almonds and walnuts, for Type Bs and Os (pumpkin seeds: good). Foods with high contents of sugar, alcohol, citrus fruits, refined carbohydrates, salt, pork in every form, as well as the blood-type specific mucus-producing foods mentioned previously, may also increase the specific mucus production of cancer cells. The common (kosher) practice of not eating other items with milk is of significant bearing in this respect because (cow's) milk produces a mucus that coats all the food, and thus prevents all the nutrients from

\author{
${ }^{2}$ Amygdalin, found in bitter almonds, apricot and peach pits, is hydrolyzed to I- \\ mandelonitrile- - glucoside and oxidized with platinum black to mandelonitrile-\$- \\ glucuronide or Laetrile ${ }^{\circledR}$ which, in turn, is turned by a ß-glucuronidase into \\ glucuronic acid, and the cancer-supressive $\mathbf{H C N}$ and benzaldehyde.
}

being absorbed. We have also been using ( $\left.\mathrm{CaNa}_{2^{-}}\right)$EDTA for chelation therapy which has been shown to reduce incidences of cancer and heart diseases by $90 \%$ and $50 \%$, respectively [1]. Likewise, increased cancer incidence may result from consumption of egg-whites and certain crustaceans, e.g., lobster, shrimp, and crayfish, due to their high content of nucleic acids which can be detrimental to the cancer patient. Therefore, the elimination of these items from diet may conceivably reduce the incidence of cancer.

\section{VITAMINS, ESSENTIAL FATTY ACIDS, AND FREE RADICALS}

The Smithsonian Institute has done a study on the incidence of cancer in sharks. They examined 25,000 sharks and found only one individual case with cancer. This suggests that the shark (e.g., genus Squalus) is most probably immune to cancer. The shark liver oil contains vitamins and other compounds with anticancer activity. This includes squalene which is also contained in cod liver and in olive oil. Squalene increases the 
polarization of the cell membrane and thereby may facilitate the action of immune system on the cancer cell. This compound is also a precursor for dehydroepiandrosterone (DHEA) which possesses anticancer activity. Moreover, squalene has been implicated in the mechanism of $\mathrm{Na}$ accumulation by the cancer cell. For example, the high uptake of $\mathrm{Na}^{+}$by the cancer cell induces an electrical potential that defies the immune mechanisms. Thereafter, both, blood forming organs and the blood cells, show a high content of $\mathrm{Na}^{+}$which can undergo desodification by squalene and certain sulphur-containing compounds also found in shark oil, such as taurine (oxidized sulfur-containing amine forming conjugates with cholic and deoxycholic acid in bile; al so a CNS neurotransmitter or neuromodulator) and isethionic acid $\left(\mathrm{HO} . \mathrm{CH}_{3} . \mathrm{CH}_{2} . \mathrm{SO}_{3} \mathrm{H}\right)$. Lithium orotate counteracts $\mathrm{Na}^{+}$retention as well and also effectively increases the monocyte and granulocyte counts. Certain vitamins, e.g., carotenes and V itamin A, are associated with low incidence of lung cancer. The excess of other vitamins, i.e., over 5 $\mathrm{g}$ of vitamin C/day, may enhance tumor growth in leukemias, and over $10 \mathrm{~g} /$ day in lymphomas and similar cancers.

It appears that the foods with the most decisive effects on the reduction of cancer incidence in humans and in animals contain omega3 unsaturated essential fatty acids (EFAs) which are also found in oils derived from linseed, chestnuts, beechnuts, soy beans, walnuts, and wheat germ. In addition, soybean and wheat germ oils contain high amounts of Vitamin E. Also rich in EFAs are cold climate legumes of which soybeans and their products, adzuki, black and pinto beans, and lentils are beneficial for blood type As, pinto and navy beans, lentils, and soybean products are beneficial for Type ABs, adzuki beans and black-eyed peas are beneficial for Type 0 s, and kidney and navy beans for Type Bs. Richest in - -3 EFAs are cold water fish of which cod, halibut, swordfish, sturgeon, and herring are beneficial for Type $\mathrm{Os}$, cod, mackerels, salmon, and trout for Type As, cod, salmon, halibut, mackerel, sardines, sturgeon and caviar for Type Bs, and cod, halibut, herrings, mackerels, tuna, and sturgeon for Type ABs. Cold-water plankton and sea vegetables are other rich sources of $\bullet-3$ EFAs. In cold climate animals, eicosasapentaenoic acid (EPA) is immediate precursor of 3-series of prostaglandins which are involved in protection of cellular functions and prevent the formation of 2-series prostaglandins which are carcinogenic. EPA inhibits formation of thromboxane A2 (TXA2) an extremely potent platel et aggregator and vasoconstrictor and antagonist of prostacyclin that may contribute to cancer by local tissue hypoxia. A diet rich in EPA also decreases elevated levels of LDL cholesterol and triglycerides, and inhibits in vitro chemotactic and aggregating activities of neutrophils.

Careful selection of oils should be considered which should be kept refrigerated and kept under a nitrogen seal until sold to prevent oxidation due to high contents of -3 EFAs in cod liver oil and other fish liver oils, and both $\bullet-3$ and $\bullet-6$ in linseed or flaxseed oil and wheat germ oil. Furthermore, in fish oils, the potential toxicity of $V$ itamins $A$ and $D$ should be considered. The use of margarine or hydrogenated oils, non-cold pressed polyunsaturated oils, shortening, bacon, grease, non-dairy creamers, egg substitutes, commercial mayonnaise and salad dressings, as well as of tropical oils like coconut oil, palm oil or cottonseed oil should be avoided. Excess amounts of polyunsaturated compounds may be oxidized which damages the cell membrane and these oxidized EFA s cannot be transported anymore into the mitochondria by carnitine and thus circulate in the bloodstream. These oxidized EFAs promote the release of free radicals which are carcinogenic, may drive LDL cholesterol from the bloodstream into the liver and body cells, and destroy HDL cholesterol and interfere with the HDL -associated lecithin-cholesterol acyl transferase (LCAT). N ote that terminal cancers consistently have HDL levels from 0.0 to $20.0 \mathrm{mg} / \mathrm{dL}$ and total cholesterol levels from 20.0 (!) to $120 \mathrm{mg} / \mathrm{dL}$ which seem to be the most reliable indicators of the life expectancy of the patient, and HDL levels under $30 \mathrm{mg} / \mathrm{dL}$ and total cholesterol under.150 mg/dL should prompt a workup to rule out a cancer. [For further details see A uthor's Note under (3) at the end of this article]
Oxidized EFAs also cause a significant elevation of uric acid (indicating destruction of cellular nucleoprotein), cause iron deficiency and anemia, liver disease, intestinal damage and obstruction, amyloidosis (abnormal waxy deposits in tissues), hypertension, gallstones, and increase the incidence of atherogenesis (formation of artherosclerosis). Free radical induction from overheating fats is also due to formation of the highly toxic from decomposition of glycerin. Note that acrolein is one of the degradation products of cyclophosphamide, used in cancer chemotherapy, and is thought to be the cause of hemorrhagic cystitis and bladder cancer in patients treated with cyclophosphamide. [See also Appendix III: Dietary Carcinogens]

In subtropical or tropical climates the use of "southern oils" is recommended. These include light and dark sesame oil, sunflower and safflower (not for Type Os, Bs, and ABs), and especially, virgin olive oil (beneficial to all blood types, as is walnut oil) which contain small amounts of the anticancer shark factor squalene. The foregoing observations suggest the use of cod liver oil (except for Type 0 nonsecretors) for several months to increase EPA intake, and to administer in addition $6000 \mathrm{U}$ of $\mathrm{V}$ itamin $\mathrm{A}$ and $600 \mathrm{U}$ of Vitamin $\mathrm{E}$. Other supplements will be wheat germ oil (not for Type 0 s) to provide energy from octacosanol and to improve physical fitness. Sesame oil may be advantageous against various bleedings, i.e., nose, gastrointestinal and gynecological bleedings. The supplement EPA can be given as concentrate or by consumption of EPA - rich foods which may also be beneficial in certain heart, blood vessel, bowel, and immune diseases, as well as cancer. In temperate climates, the caloric intake from EFAs should be approximately $2 \%$ to $3 \%$. Furthermore, gamma linolenic acid from evening primrose oil has been found, via synthesis of the series-1 prostaglandins, most notably prostaglandin $E_{1}$ $\left(P E_{1}\right)$, to decrease elevated LDL cholesterol levels, lower blood pressure by vasodilatation, inhibit thrombosis/platelet aggregation, and to normalize cancer cells.

\section{OXYGENATION (see Appendix I)}

It is generally assumed that healthy cells resist becoming cancerous if they are provided with adequate nutrients. Insufficient supply of a given critical nutrient may lead to or facilitate cancer induction. The same is true of the amount of oxygen reaching the cells since low cellular oxygen levels may result in anaerobic conditions which will further cancer development. The lack of oxygen has long been suspected in carcinogenesis because it leads to an anaerobic metabolism where, essentially, glucose is converted into lactic acid and the $\mathrm{pH}$ in the cancer cells becomes acidic. The acidic $\mathrm{pH}$ because of lack of $\mathrm{O}_{2}$ may cause breakdown of RNA and DNA and damage the cellular control mechanisms involved. The development of acidic toxins usually will lead to the destruction of cell structures. Therefore, reversing this condition requires adequate oxygenation. There are certain elements, e.g., germanium, which may prove beneficial for cellular oxygenation. Germanium possesses 8 valences and therefore can carry 4 atoms of oxygen and may provide the oxygenation needed for the cancer cell to evoke anticancer effect. Ginseng normally grows only on germanium rich soil and should provide a good source for this phenomenon. However, the use of soil antibiotics in homegrown ginseng may interfere in the production of an effective ginseng due to its lack of soil derived germanium. This sensitivity of cancer cells to oxygenation explains, in part, the effectiveness of oxidative therapies, such as hydrogen peroxide and, particularly, ozone, in certain cancers. Ozone, especially directly I.V., in the author's experience, without any doubt, greatly enhances the effects of all cancer therapies including the one suggested herein.

Certain antioxidant in food preservatives, e.g., butylated hydroxytoluene, butylated hydroxyanisole, and 5,6-benzoflavone may possess anticancer activity. Ornithine, arginine, and $I G F_{1}$ and other amino acids stimulate/modulate human growth hormone secretion/action, and thus enhance the immune system, reverse uncontrolled cancer growth, and suppress prolactin production. 


\section{INORGANIC COM POUNDS AND ELEMENTS}

The presence of certain elements in diet is as important as the choice of diet for reducing the incidence of cancer and even in the management of the cancer patient. For example, selenium deficiency has been associated with increased cancer incidence. Other elements with some anticancer activity include molybdenum, zinc, magnesium, and germanium.

B rewer's [2] analyses of reports dealing with certain regions of the world with low incidence of cancer has motivated his rationale for the high $\mathrm{pH}$ therapy for cancer. This was primarily based on the high amounts of cesium and rubidium found in the food consumed in these areas, most notably the Hopi Indian territory in A rizona, H unza L and in N orthern Pakistan, vol canic areas in H awaii, A ustria, and in selected regions of K enya and Brazil. This represents a novel approach in cancer chemotherapy based on changes in cancer cell $\mathrm{pH}$ and possible inactivation of ionic hydrogen of the tumor cell to reduce acidity. This approach has been referred to as "high $\mathrm{pH}$ " therapy. A combined effect of low $\mathrm{pH}$ and high body temperature has been also suggested in cancer treatment and termed the "low $\mathrm{pH}^{\prime \prime}$ therapy. B oth $\mathrm{pH}$ therapies are briefly outlined below; the low $\mathrm{pH}$ therapy was devised by $\mathrm{V}$ on Ardenne [8] and the high $\mathrm{pH}$ therapy by Brewer [2]. B oth have been shown to be effective therapeutic measures for the treatment of cancer in laboratory animals and humans.

\section{LOW-pH Therapy}

In this therapy, glucose is injected into the blood stream. As a consequence the cancer cell $\mathrm{pH}$ drops to the 5.5 range. The patient is then placed in a chamber heated from 45 to $50^{\circ} \mathrm{C}\left(113\right.$ to $\left.122^{\circ} \mathrm{F}\right)$ for 4 to 6 hrs [8]. Diathermy is also applied over the tumor area which, in the absence of a blood supply, will cause the temperature of the tumor mass to rise to over $55^{\circ}\left(133^{\circ} \mathrm{F}\right)$. At these high temperatures, the life of cancer cells is observed to be very short. An apparent drawback to the therapy is that a case of severe toxemia may result because of leakage of acidic and toxic material from the tumor masses [8].[See "H yperthermia" in A ppendix]

\section{HIGH - pH Therapy}

The rapid uptake of cesium and rubidium observed for cancer cells is the theoretical approach of high $\mathrm{pH}$ therapy [2]. This therapy has been tested using $\mathrm{CsCl}$ or $\mathrm{Cs}_{2} \mathrm{CO} 3$ in conjunction with the administration of ascorbic and retinoic acids, zinc and selenium salts. The weak acids which are absorbed by the tumor cells have been shown to enhance the negative potential gradient across the membrane. Zinc and sel enium salts, when absorbed on the membrane surface, act as broad and moderately strong electron donors. These ions and salts have been shown in mice to drastically enhance the uptake of cesium and rubidium ions. For treatment of cancer patients the administration of 6 to $9 \mathrm{~g}$ of $\mathrm{CsCl}$ or $\mathrm{CsCO}_{3}$ for several days is believed to be tolerable and sufficient to raise the $\mathrm{pH}$ in the tumor cells to a weak alkaline level of approximately $\mathrm{pH} 8$ where the life cancer cell is shortened. In addition, the presence of cesium and rubidium salts in the body fluid is expected to neutralize the acidic and toxic material emanating from the disintegrating tumor mass.

Results from both animal experiments, mainly through M essiha [6], and these of ours in limited clinical trial in humans in our clinic [7], are indicative of a high success rate of Cs treatment in cancer therapy.

Thus, both dietary factors and selected elements and vitamins may play a more significant role in the pathogenesis and pathology of certain cancers than has been previously accounted for. Moreover, changes in dietary habits may have a lasting effect on protection against cancer development and progression

To conclude, the author presents a list of cancer protective nutrients and their main functions and importance outlined in Table I. A ppendix III lists "Naturally Occurring Dietary Carcinogens".

\section{ACKNOW LEDGEMENT}

The helpful assistance of Dr. Fathi S. Messiha in the preparation of this manuscript is gratefully acknowledged.

\section{REFERENCES}

1. Blumer, W. and T. H. Reich. Leaded gasoline: a cause of cancer. Environ Int 3: 465-471. 1980.

2. B rewer, A. K. M echanism of carcinogenesis: Comments on therapy. J Int Acad Prev Med 5: 29-53. 1979.

3. Graille, J.-M. Dossier Priore, une Nouvelle Affaire Pasteur. Paris: E ditions Denöel. 1984

4. Kushi, M ichio. Cancer and Heart Disease: The Macrobiotic Approach to Degenerative Disease. Tokyo: J apan Publications Inc. 1982.

AUTHOR'S NOTE: Certain parts of the original manuscript that was submitted for publication were deleted by the editor of this journal as being too controversial or not sufficiently proven to warrant inclusion in this article. This slightly edited version restores the text of the original manuscript and in some places clarifies where all too terse language may have obscured the intended meaning. Specific areas that at the time of the publication were too controversial include:

(1) A ny reference to the therapeutic use of oxidative therapies, in particular, direct I.V . ozone

(2) Any reference to any blood-type specific individual nutritional requirements as this, in 1984, was virtually unexplored, except for J ames D 'A damo in Portsmouth, N.H. and the author, and where the latter found that almost all the failures of vegetable only approaches to cancer, including Michio Kushi's, were Type Os, whereas, generally, Type As responded to these therapies.

(3) Extremely low serum cholesterol levels (in $\mathrm{mg} / \mathrm{dL}$ ) as the most reliable indicators for the survival potential of terminal cancer patients, e.g., $0.0 \mathrm{HDL} \&<20$ total at most 48 hours, $<5.0 \mathrm{HDL} \&$ $<40$ total at most 1 week, $<10 \mathrm{HDL} \&<60$ total at most 2 weeks, $<15 \mathrm{HDL} \&<80$ total at most 1 month, $<20 \mathrm{HDL} \&<100$ total at most 3 months, $<25 \mathrm{HDL} \&<125$ total at most 1 year, which was consistently found in untreated patients or the ones refusing treatment at our clinic.
5. Kushi, M ichio. The Cancer Prevention Diet, Michio Kushi's Nutrirional Blueprint for the Relief and Prevention of Disease. New Y ork: St. M artin's Press. 1983.

6. M essiha, F. S., A. EI-D omeiri, and H. F. Sproat. Effects of lithium and cesium salts on sarcomal implants in the mouse. Neurobehav Toxicol 1: 27-31. 1979.

7. Sartori, H. E. Cancer 1984. Orwellian or Eutopian. Washington.DC: Life Science U niversal M edical Center. 1984.

8. V on A rdenne, M. Hyperthermia and cancer therapy. Oncol Chemother Pharmacol 4: 137-139. 1980.

\section{Blood Type A (and AB) High Cancer Risk Profile:}

(1) Thomsen-Friedenreich [Tn (GalN AC...) \& T (Gal• 1 3GalNA C...)] antigens/epitopes, found in $\sim 90 \%$ of all cancers/metastases, B-cell Iymphomas (human Iymphotropic virus Type II-induced), \& multiple myeloma, resemble the Type $A$ antigen (GalN Ac...). This impairs the ability of the immune system of Type $A s(\& A B s)$ to recognize malignant cells and also weakens NK cell activity. Thus, Type As are at increased risk for most cancers, except bladder cancers where Os and Bs at the highest risk, pancreas, liver, \& esophagus cancers where only $\mathrm{Os}$ are low risk, whereas $\mathrm{Os}$ in melanomas and Bs in bone cancers are at the highest risk. Note that the specific lectin of the escargot snail, Helix pomatia, unmasks $\mathrm{T} \& \mathrm{Tn}$ antigens in (pre)cancerous cells. Regular intake of escargots is recommended nutritional treatment for all Type $A s(\& A B s)$ as cancer-preventative and may hel $p$ reverse breast cancers and lymphomas.

(2) Type As with metastatic cancer show elevated fibrinogen, factor VIII, and von Willebrand factor (VWF) which attach to an aberrant platel et glycoprotein that, in turn, attaches to cancer cells and thus causes metastasis. Heparin and other blood thinners effectively prevent this type of metastasis.

(3) Type As have the greatest tendency to manifest a "cancer personality" which is explained in "Cesium Therapy in Cancer Patients", infra, in these proceedings. 


\title{
Cesium Therapy in Cancer Patients
}

\author{
H. E. SARTORI, M.D. \\ Life Science Universal Medical Center, Suite 306 \\ 4501 Connecticut A venue, Washington, DC 20008
}

\begin{abstract}
SARTORI. H. E. Cesium Therapy in Cancer Patients. PHARM ACOL BIOCHEM BEHAV 21: Suppl. I: 11-13. 1984 - The effect of cesium therapy on various cancers is reported. A total of 50 patients were treated over a 3 year period with $\mathrm{CsCl}$. The majority of the patients has been unresponsive to previous maximal modalities of cancer treatment and was considered terminal cases. The C s-treatment consisted of $\mathrm{CsCl}$ in addition to some vitamins, minerals, chelating agents, and salts of sel enium, potassium and magnesium. In addition, a special diet was instituted. There was an impressive 5 year recovery of various cancers, including, cancers of unknown primary, breast, colon, prostate, pancreas, lung, and liver, lymphoma, Ewing sarcoma of the pelvis, and adenocarcinoma of the gallbladder by the Cstherapy employed. There was a $26 \%$ and $24 \%$ death within the initial 2 weeks and 12 months of treatment, respectively. A consistent finding in these patients was the disappearance of pain within the initial 3 days of Cs-treatment. The small number of autopsies made showed the absence of cancer cells in most cases and the clinical impression indicates a remarkably successful outcome of treatment.
\end{abstract}
Cancer
Cancer personality
Cesium
Diet
Humans
Minerals
Vitamins

CERTAIN foods contain biologically active compounds and/or ingredients, i.e., vitamins, inorganic salts, organic compounds, essential fatty acids, minerals, and chelating agents which may either precipitate or prevent cancer development. The relationship between dietary consumption and cancer development is not clear and further investigation continues [5]. Noteworthy is the report [3] on the presence of high levels of cesium (Cs) and rubidium $(R b)$ in food along with availability of various supportive compounds such as vita mins $A$ and $C$ along with zinc and selenium in diet of populations residing in areas with low incidence of cancer, e.g., the Hopi Indian territory in Arizona, the Hunza Land in Northern Pakistan, Vilcabamba, Ecuador, and the vol canic regions of B razil. The diet of these populations is similar to the nutritive requirements for the high $\mathrm{pH}$ cancer therapy developed by B rewer [2] after a series of physical experiments with cancer cells. In these tests the presence of $\mathrm{Cs}^{+}$or $\mathrm{Rb}^{+}$in the fluids adjacent to the tumor cells is believed to raise the $\mathrm{pH}$ of the cancer cells where cell mitosis will then cease resulting in reduction of life span of the cancer cell. The introduction of such al kaline $\mathrm{pH}$ by these alkali salts may also neutralize the acidic and toxic material within the cancer cell. This report combines the use of $\mathrm{CsCl}$ with various supportive agents, which have been hypothesized both to enhance the entry of $\mathrm{Cs}$ into the cancer cell and to stimulate the immune response, in the treatment of various cancers.

\section{METHOD}

Treatment was performed on 50 patients during the last three years at Life Science Universal M edical Center Clinics in Rockville, $M$ aryland and in Washington, D.C. All patients were terminal subjects with generalized metastatic disease. Forty-seven of the 50 patients studied had received maximal modalities of conventional treatment, i.e., surgery, radiation, and various chemotherapies, before the metabolic Cs-treatment was initiated. Three patients were comatose and 14 of the patients were considered terminal due to previous treatment outcomes and cancer complications. The type of cancer of studied and the number of patients is detailed in Table I.

The Cs-treatment was given in conjunction with other supportive compounds. The patients were maintained on a cancer control diet. In addition, specific compounds and modalities were used to produce adequate circulation and oxygenation. According to individual cases, $\mathrm{CsCl}$ was given in daily dosages of 6 to $9 \mathrm{~g}$, in three equally divided doses, in conjunction with vitamin $\mathrm{A}$ emulsion (100.000 to 300.000 I.U.), vitamin E (400 to 1000 I.U.), vitamin C (4 to $30 \mathrm{~g}$ ), zinc ( 80 to $100 \mathrm{mg}$ ), selenium (600 to $1,200 \mathrm{mcg}$ ), and amygdalin (1,500 mg). Other supplementations were used according to the specific needs of the patient. The diet consisted mainly of brown rice, root and leafy vegetables, linolenic acid rich oils [linseed = flaxseed and walnut; soy (not for blood type 0 and B), wheat germ (not for Type Os)] and other supplemental foods. To increase the efficiency of the treatment and to improve the circulation and oxygenation, the patients received the chelating agent $\left(\mathrm{CaNa}_{2}\right)$ EDTA, dimethylsulfoxide (DMSO), and also a combination of vitamins, and $\mathrm{K}$ and $\mathrm{Mg}$ salts.

\section{RESULTS}

Table I summarizes the results of the Cs-treatment of 50 cancer patients studied for over 3 years. They had generalized metastatic disease, except for 3 patients. Initial death occurrences for the initial 2 weeks of treatment were in the same order and magnitude as these recorded for the 12 month period. The percent of survival of patients with breast, colon, prostate, and pancreas and cancers of unknown primary was $50 \%$, while 3 out of 5 lung cancer patients, 2 out of 3 lymphoma patients, and one out 3 liver cancer patients treated in this series survived. An overall 50\% recovery from cancer by the Cstherapy was determined in the 50 patients treated. Data from the autopsies made indicated the absence of tumors in patients dying within 14 days of the $\mathrm{Cs}$-treatment.

One of the most striking effects of the treatment was the disappearance of pain in all patients within one to three days after initiation of the treatment. The disappearance of pain may be explained by changing the acidic $\mathrm{pH}$ that triggers the pain in the pain receptors to slightly alkaline where all pain sensations disappear. This does not only apply to cancer pain but also to arthritic and neuralgic pain that also consistently disappear after application of $\mathrm{Cs}, \mathrm{Rb}, \mathrm{K}$, $\mathrm{Mg}$, and $\mathrm{Ca}$, in descending order of effectiveness. Pain relief from alkalinizing agents is primarily a function of a general shift of the body's acid-base balance towards the alkaline that takes place preferentially in acidic areas and is a principle that was known in medicine since ancient times (see, e.g., Huáng Dì Nèi J ^ng, The B ook of Internal M edicine of the Y ellow Emperor). 
TABLE I

THE EFFECT OF CSCITREATM ENT ON VARIOUS ADVANCED TY PES OF CANCER IN MAN

M orbidity Time Post Therapy

\begin{tabular}{lcccc} 
Tumor & (n) & 14 Days & 12 Months & Number of Survivals \\
B reast** & $(10)$ & $3^{*}$ & 2 & 5 \\
Unknown Primary & $(8)$ & $2^{*}$ & 2 & 4 \\
Colon & $(9)$ & 2 & 2 & 5 \\
Prostate & $(6)$ & $1 *$ & 2 & 3 \\
Pancreas & $(4)$ & 1 & 1 & 3 \\
Lung & $(5)$ & 1 & 1 & 1 \\
Liver & $(3)$ & $1 *$ & - & - \\
Lymphoma & $(3)$ & 1 & - & - \\
Ewing Sarcoma Pelvis & $(1)$ & & \multicolumn{2}{l}{} \\
A denocancer of Gall bladder & $(1)$ & 13 & 12 & \\
& & &
\end{tabular}

These studies were performed under my direction, initiated in April 1981. Forty-eight patients were initially treated with $\mathrm{CsCl}$ between A pril 1981 and October 1982. They were subjected to various conventional cancer therapies such as surgery, radiation, and chemotherapy, and were considered terminal cases with general metastatic disease, except for 3 patients who were not previously treated. Three patients were comatose at the time of the Cs treatment. Thirteen patients died within less than 2 weeks of treatment. Each patient showed a reduction in tumor mass by the $\mathrm{Cs}$ treatment. Of the breast cancer patients, the most impressive effect was seen in a 44 year old housewife who was comatose at the beginning of the Cs-treatment and was considered a terminal case with a life expectancy of at most of one week. The Cs-therapy, with the other ingredients used, was immediately instituted by the nasogastric route because there was no cooperation of the patient for regular oral administration possible. The daily $\mathrm{CsCl}$ dose amounted to 30 grams in three divided doses of 10 grams each. The patient regained consciousness within 24 hours after the initiation of the treatment and she was ready to leave her bed after five days on the therapy. However, when attempting to get out of her bed, a fall that resulted in a fracture of cervical vertebra 2 caused her unfortunate demise within another 48 hours. The autopsy revealed that cancer metastasis had essentially "eaten away" parts of the neck, head, and trochanter of her hip bone causing this tragic accident.

The next most frequent cancer treated was of unknown primary. Treatment of 8 cases showed a death rate of 2 within 14 days of treatment and an additional 2 deaths within 12 months while 4 of the patients are still living. In one case, an autopsy was made in a patient after one week of C s treatment and showed a complete disappearance of the cancer. Thos patient's death was attributed to the fulminant cardiotoxicity from her treatment with doxorubicin $\mathrm{HCl}$ (Adriamycin ${ }^{\circledR}$ ) that had resulted in an intractable congestive heart failure. There were 7 cases of colon cancer patients who were treated with $\mathrm{CsCl}$. Two of these patients died within 14 days. One of these two patients had previous massive chemotherapy and too little time was available to restore her bone marrow depression and dysmetabolic condition. The previously existing infiltration of the abdominal wall had disappeared in both patients. However, no consent was given for an autopsy.

In one lymphoma case the patient displayed a maximally extended spherical abdomen which was hard and he weighed approximately $112 \mathrm{~kg}$ (250 pounds). This massively enlarged abdomen progressively reduced in size with a loss of approximately
$55 \mathrm{~kg}$ (121 lbs) of body weight after 3 months on the Cs therapy. Of this weight loss $30 \mathrm{~kg}$ (66 lbs) was attributed to ascites and $25 \mathrm{~kg}$ (55 lbs) to reduction of the tumor mass. The spleen which was originally maximally enlarged and reaching into the pelvis, was reduced to almost normal. The liver position was down to about the level of umbilicus and was reduced to normal size in 3 months. The patient is still living 3 years after his discharge. Unfortunately there was no follow-up on this patient and he is maintained on chemotherapy.

\section{DISCUSSION}

The results presented demonstrate the rate of efficacy of $\mathrm{CsCl}$ in cancer therapy. The total of 50 cancer cases shows an impressive $50 \%$ survival rate. This confirms the work of M essiha reported elsewhere in these proceedings showing that the higher the dose the more effective it seems. The autopsy obtained from the patient whose death was attributed to a traumatic fracture of the neck, indicates that the cancer has been initially further advanced resulting in bone destruction. However, the absence of cancer after the massive $\mathrm{CsCl}$ dose used in this case is demonstrable of the therapy. It appears that both dosage, i.e., as much as 30 grams/day, and route of drug administration, i.e., the nasogastric pathway, might have contributed to the patient's rapid recovery. It should be noted, however, that the oral $\mathrm{CsCl}$ dosage in humans should not exceed 20 to 40 grams/day to avoid side effects, notably nausea and diarrhea. The author's personal experience with $\mathrm{CsCl}$ after an acute dose of $40 \mathrm{~g} \mathrm{CsCl}$ indicates that extended nausea and paresthesias around the mouth are the major side effects. The latter is probably due to $\mathrm{K}$ depletion. The usual doses used in the clinic ranges from 2 to $3 \mathrm{~g}$ given by mouth 3 times daily. At a latter time, at which time there is no indication of cancer presence, the $\mathrm{CsCl}$ dosage will be reduced to a preventative dose between 0.75 to $1.5 \mathrm{~g}$ a day. Less than $10 \mathrm{mg} / \mathrm{kg}$ or $0.6 \mathrm{~g} / 60 \mathrm{~kg}$ of $\mathrm{CsCl}$ may enhance cancer growth.

The lymphoma case presented shows that $\mathrm{CsCl}$ efficiently reduced massive enlargements of spleen and liver as well as maximum ascites, causing an abdominal configuration of a tight, hard hemisphere to almost normalize after 3 months of therapy. This period of time was required to eliminate such a massive volume, resulting in the reduction of the body weight noted 
The clinical efficacy of $\mathrm{CsCl}$ high $\mathrm{pH}$ metabolic therapy is best demonstrated by a recent case of primary liver cancer (not included in the 50 cases reported in this study). The patient was a 39 year old female school teacher who was terminal. She was brought in the clinic on a stretcher on A pril 25, 1984 with a large liver tumor extending approximately $3 \mathrm{~cm}$ below the umbilical level with numerous large hard nodes ranging from 1.0 to over $5 \mathrm{~cm} \mathrm{(2/5} \mathrm{to} \mathrm{>}$ $2^{\prime \prime}$ ) in diameter. The treatment was then immediately instituted. This consisted of administration of $\mathrm{CsCl}, \cdot$-carotene, vitamins $\mathrm{A}$ and $\mathrm{C}$, $\mathrm{Zn}, \mathrm{Se}, \mathrm{Mn}, \mathrm{Cr}$ and $\mathrm{K}$ salts by the oral route in addition to $\mathrm{a}$ concomitant massive I.V. doses of ascorbate, as well as $\mathrm{K}, \mathrm{Mg}, \mathrm{Zn}$, $\mathrm{Cu}, \mathrm{Mn}$, and $\mathrm{Cr}$ salts, B-complex vitamins, folic acid, DM SO and heparin. After five consecutive treatment regimens, EDTA was introduced to the therapy and the minerals present in the IV solution were discontinued. On M ay 10, 1984, the patient was discharged, returned home walking without assistance and displaying a pleasant smile on her face. The tumor- infiltrated liver had shrunk to $5 \mathrm{~cm}$ above the umbilicus or normal size and showed a smooth surface without any noticeable nodes. The determination of alphafetoprotein (AFP), a specific marker for liver cancers, and rare embryonic cancers and teratomas, decreased from an unusual high value of 39,000 units $(120,000 \cdot \mathrm{g} / \mathrm{L})$, compared to normal levels of $<13$ units $(<40 \cdot \mathrm{g} / \mathrm{L})$, seen before initiation of Cs-therapy, to 5,000 units $(150,000 \cdot \mathrm{g} / \mathrm{L})$ obtained on the last day of treatment.

The mechanism of action of $\mathrm{Cs}$ in cancer has been little studied. That both $\mathrm{Cs}^{-}$and $\mathrm{Rb}^{-}$can specifically enter cancer cells and embryonic cells, but not normal adult cells, has been demonstrated by Brewer [2]. The cancer cells contain high amounts of hydrogen ions rendering them acidic and they also contain higher $\mathrm{Na}^{+}$levels than found in normal cells. If $\mathrm{Cs}^{-}$or $\mathrm{Rb}^{-}$enter the cancer cells, their $\mathrm{pH}$ increases from as low as 5.5 to over $\mathrm{pH} 7.0$. At a pH of 7.6 the cancer cell division will stop, and at a pH of 8.0 to 8.5 the life span of cancer cells is considerably shortened (to only hours). In one case, the author has observed the shrinkage of metastases of breast cancer one hour after Cs-treatment. Two days later wrinkles of the skin appeared where the tumor had been present. In another case of a colon cancer with massive metastasis, the massive infiltration of the abdominal wall, the liver and of other tissues seemed to have been reduced within 24 hours and was continuing rapidly until the demise of the patient on the 14th day of the Cs-treatment.

The uric acid levels measured at the onset of treatment were approximately $3.5 \mathrm{mg} / \mathrm{dL}$ (normal: 2.0 to $8.0 \mathrm{mg} / \mathrm{dL}$ ) which was increased to over $20 \mathrm{mg} / \mathrm{dL}$ suggesting massive breakdown of DNA, specifically, the purine nucleotides adenosine and guanosine which are catabolized to uric acid. Therefore, destruction of nuclear acids, as reflected by a significant rise in serum uric acid, may be used as predictive measurements for treatment outcome. The failure of serum uric acid elevation may be indicative of lack of destruction of cancer cells. This has proven to be a very consistent finding in our clinic. There are certain factors which may enhance the C s therapy. The $\mathrm{Cs}^{+}$ penetration into the cancer cell can be increased by the following three methods: The first approach resides in broadening the electron donor capacity of the cancer cell membrane by the application of cyanide $\left(\mathrm{CN}^{-}\right)$, an electron donor radical found in nitriles (amygdalin, Laetrile ${ }^{\circledR}$ or mandel onitrile, prunasin, ficin, or cassivin), by selenium and zinc ions, which are electron donor radicals, or by the use of DM SO. The second approach enhances the potential gradient across the cancer cell membrane by the utilization of weak acids like ascorbic acid (V itamin C) and retinoic acid (Vitamin A). The third method attempts to improve the circulation to the tumor and facilitate the destruction of cross linkages in the mucoid and fibrinous substances around the cancer cell. This can be achieved by chelation therapy. i.e., the use of EDTA, preferably $\mathrm{CaNa}_{2}$-EDTA directly I.V., as has been shown by Blumer (1), who reported on the reduction of cancer incidence by $90 \%$ by chelating patients (an average of 15 chelations in 8 years). This approach also reduced cardiovascular disease by $50 \%$. Other chelating agents can be also used. M oreover, the use of beta-carotene will lead to decomposition of blocking mucoid proteins which is mediated by electrical charges. Heparin which also acts through electrical charges will inactivate the immune repelling and immune binding capacities of the blocking mucoid proteins. These approaches will hinder cancer growth and they are virtually atoxic.

It should be noted that certain behavioral characteristics, "the cancer personality" of the cancer patient, may interfere in any projected treatment modality. This has been reported by Lawrence LeShan [4] in his book entitled "Y ou Can Fight for Y our Life." His studies suggested that cancer patients seeking treatment, e.g., chemotherapy, radiation or surgery are probably motivated by a covert desire for death. They fail to express statements such as, "rather than undergoing any of those treatments, I would rather die in peace," or "I would never undergo any of those treatments or let anyone of my family undergo them because the effectiveness is unproven, and the damage that is done with any of those treatments is higher than the effects", and willingly and in spite of the obvious failure of the treatments and the sometimes horrendous side effects of chemotherapy opt for repeated courses of it until their eventual demise. The most important psychological factors contributing to cancer are loss of a crucial relationship, both personal and professional, inability to express hostility or even show anger or aggression in self-defense, death of sibling or parent in early childhood causing tension, high degree of self-dislike or self-distrust, being programmed since early childhood that emotional relationships are dangerous and unsatisfying, being widowed, and, above all bleak, existential, passionless hopelessness and despair about ever achieving any meaning or validity in life. At the deepest emotional level, these people do not relate since they believe to be unworthy of love and summarize their lives as, "I've done nothing and been nothing". [See also Note, below]. Thus, both, nutritional intake, as suggested herein, and lifestyle/psychological changes may contribute to an effective therapy of cancer (and other degenerative diseases).

\section{ACKNOWLEDGEMENT}

The helpful assistance of Dr. Fathi S. M essiha in the preparation of this manuscript is gratefully acknowledged

\section{REFERENCES}

1. Blumer, W . and T. H. Reich. L eaded gasoline: A cause of cancer. Environ Intern 3: 465-471. 1980.

2. B rewer, K. A. M echanism of carcinogenesis: Comments on therapy. J Int Acad Prev Med 5: 29--53. 1979.

3. Calloway, R. D., R. Giauque, and F. M. Costa. Superior mineral content of some A merican Indian Foods in comparison to F ederal counterpart conated commodities. Ecol Food Nutr 3:203-208, 1974.

4. Le Shan, L. You Can Fight For Your Life. Emotional Factors in the Treatment of Cancer. N ew Y ork: M. Evans and Comp.,1977.

5. Special Report. Food and Cancer. Nutr Rev 24: 313-323. 1978.
Note: The connection between Blood Type and Cancer has been addressed in the endnote to the slightly edited "N utrients and Cancer: An Introduction to Cesium Therapy", supra, in these proceedings, particularly, the proneness of Type As towards exhibiting the traits of "cancer personalities".

AUTHOR'S NOTE: Certain parts of the original manuscript that was submitted for publication were deleted by the editor of this journal as being too controversial or not sufficiently proven to warrant inclusion in this article. This slightly edited version restores the text of the original manuscript and on some places clarifies where all too terse language may have obscured the intended meaning. 


\section{APPENDIX I: COMMENTS ON OXYGENATION \& OZONATION}

EFFECTIVE CANCER TREATMENT \& PREVENTION

The foll owing methods are effective with virtually no adverse effects: (a) Nutrition and lifestyle of longevity populations that consume foods rich in the nutrients that are the basis of the high $\mathrm{pH}$ therapy discussed in "Nutrients and Cancer", supra, and where high doses of these nutrients, especially if applied I.V., are by far the most effective treatment of cancer. Also, their low stress/high physical activity lifestyle is important in cancer prevention as is the ozone-rich air in the high altitudes in which they live. See "Cesium Therapy in Cancer Patients", supra, as well as the Chapter "Ozone and Cancer" in the author's book on "Ozone", and his forthcoming book "NO M ore Cancers".

(b) Herbal treatments of cancer which were used worldwide since time immemorial including: Shark cartilage, Resistocell ${ }^{\circledR}$, the thymus preparations Thymex $\mathrm{L}^{\circledR}$ and TFZ-Thymomodulin ${ }^{\circledR}$, colostrum-derived transfer factor (TF) according to H. Hugh Fudenberg, Dr. Nieper ${ }^{1} \mathrm{~S}$ natural anticancer substances, and herbal cancer treatments such as compounded Hoksey [Trifolium pratense, Rhammus cathartica, Berberis vulgaris, Arctium lappa, Stillingia sylvatica, Rhammus purshiana or Cascara amarga (Sweetia panamensis), Glycyrrhiza glabra, Zanthoxylum clava-herculis], compounded Echinacea [Echinacea spp, Ceanothus americanus, Baptisia tinctoria, Thuja occidentalis, Stillingia sylvatica, Iris versicolor, Zanthoxylum clava-herculis], Folia Thujae occidentalis (fresh), Radix Astragali membranacei (Huáng Qí), Radix Rumicis crispi (fresh), and Renèe Caisse's Essiac compound [Rumex acetosella, Arctium lappa (fresh root), Ulmus rubra, Rheum palmatum (root), etc.], PDR Cancer Formula [Larrea divaricata (folia), Sanguinaria canadensis (radix), Trifolium pratense (flores), Arcticum lappa (radix); Echinacea purpurea (radix), Hydrastis canadensis (radix); Symphytum officinale (folia), Eleutherococcus senticosus (radix; eventually folia, radix, and flores), Chelidonium maius, combined with Artemisia absinthium, Yucca spp, and Commiphora molmol (gum), C. abyssinica (myrrh), or C. opobalsamum (bdellium-oleoresin)], Laetrile ${ }^{\circledR}$ et al. mandelonitriles, immunostimulating mushroom extracts from Grifola frondosa (maitake), Ganoderma lucidum (reishi), and Lentinus edodes (shiitake), combined with herbs for specific cancers; e.g., herba Hedyotis diffusae (bái hu• shé c•o) combined with herba Scutellariae barbatae (bàn zh• lían) for stomach, esophageal, \& colon cancers, \& the latter alone for lung cancers, \& tuber Dioscoreae bulbiferae (huáng yào $\mathrm{z}^{\bullet}$ ) for thyroid cancer \& endemic goiter, and, especially, Haelan $851^{\circledR}$ Platinum Formula and Nature's Blessing.

(c) Oxidative Cancer Therapies are effective since the anaerobic cancer cells are highly sensitive to oxidants/electron donors. The most powerful of the naturally occurring electron donors is ozone that is found in clinically significant concentrations in the air in altitudes above $1800 \mathrm{~m}(6000 \mathrm{ft})$ and where cancer is virtually nonexistent in people living above $3000 \mathrm{~m}(10,000 \mathrm{ft})$.

The most effective herbal electron donors that restore the body to an alkaline balance can be found in plants containing high amounts of germanium $(\mathrm{Ge})$, an ampholyte with four unstable electrons.

Medicinal plants that reputedly have anticancer activity and that contain high amounts of Ge include shelf fungus (Trametes cinnabarina; 800-2000 ppm), Ginseng (Panax ginseng; 250-350 Korean < 4000ppm), garlic (Allium sativum; $750 \mathrm{ppm}), \mathrm{d} \bullet \mathrm{ng}$-sh $\bullet \mathrm{n} / \mathrm{sansukon} \operatorname{root}($ Codonopsis pilosula; $260 \mathrm{ppm}$ ), sushi (Angelica pubescens; $260 \mathrm{ppm}$ ), Bandai moss (260 ppm), Japanese waternut (Trapa japonica: $240 \mathrm{ppm}$ ), Comfrey (Symphytum officinale; $150 \mathrm{ppm}$ ), boxthorn seed (Lycium chinense; $125 \mathrm{ppm}$ ), wisteria $\mathrm{knob} /$ gall (Wisteria floribunda; $110 \mathrm{ppm}$ ), pearl barley (fructus coicis lacryma-jobi; $75 \mathrm{ppm})$, etc.

Based on this concept, Kazuhiko Asai synthesized numerous non-toxic Ge compounds, most notably, propagermanium or biscarboxyethyl $\mathrm{Ge}$ sesquioxide $\left[\mathrm{O}_{3}\left(\mathrm{Ge} \cdot \mathrm{CH}_{2} \cdot \mathrm{CH}_{2} \cdot \mathrm{COOH}\right)_{2}\right]$, which has been found effective in the prevention and treatment of numerous cancers and their metastases including cancers of the lungs, prostate, breast, liver, kidney, brain tumors, lymphomas and leukemias, and sarcomas such as chondro- and osteosarcomas. The recommended dosage for prevention is 100 to $200 \mathrm{mg} /$ day and for treatment 1000 to $4000 \mathrm{mg} /$ day for a $60 \mathrm{~kg}$ patient. Except for a Herxheimer-type "healing crisis" reaction, no other adverse effects have been observed with this compound. If no effect is seen, the treatment should be discontinued after 60 days. (d) Medical Ozone is the most powerful oxidative therapy, used in cancer treatment since the early 1920s, and where the DIRECT I.V. $\mathrm{O}_{3}$ Application has the following advantages:

(1) EFFECTIVENESS of $\mathrm{O}_{3}$ in the treatment of all cancers, including leukemia, lymphomas and sarcomas. Direct I.V. $\mathrm{O}_{3}$ is particularly effective for lung cancers.

(2) Consistently better results compared with the LAHT. Direct I.V. application produces much faster results and requires fewer applications than LAHT. This is particularly apparent in patients with lung cancer \& sarcoids, allergies, \& AIDS.

(3) Prompt elimination of any allergic component contributing to cancer formation, e.g., by increasing the oxygen diffusion distance. This direct $\mathbf{I} . \mathbf{V} . \mathbf{O}_{3}$ effect is much more consistent than with LAHT. The same applies to removal of viruses, bacteria, and fungi that may be adjunctive cancer factors. Direct I.V. $\mathrm{O}_{3}$ consistently removes unwanted antibodies from the bloodstream, and seroconversions from HIV positive to HIV negative have been observed after only three to four consecutive administrations at the recommended dosage if patients are adequately supplemented, particularly with $\mathrm{Zn}$, $\mathrm{Se}$, vitamins $\mathrm{A} \& \mathrm{E}, \& \cdot$-carotene.

(4) Clean application of the ozone with simple syringes without the requirement of using disposable AHT bottles and other equipment that could be contaminated with blood-borne infectious agents, particularly, hepatitis $\mathrm{C}$ and $\mathrm{B}$ virus ( $\mathrm{HCV}$ and $\mathrm{HBV}$ ), syphilis-treponema ( $T$. pallidum), Babesia spp (Babesiosis), Plasmodium spp (Malaria), Trypanosoma spp (Trypanosomiasis), cytomegalovirus (CMV), Epstein-Barr virus (EBV), herpes simplex virus (HSV), human T-cell leukemia virus 1 \& 2 (HTLV-1 $\& 2$ ), the orbivirus of Colorado Tick Fever, etc.

(5) Precise dosage since there is no reaction with the vitamin $\mathrm{C}$ that most German researchers suggest be added to the large autohemotransfusion (LAHT).

(6) Homeopathic effect of direct I.V.ozone : The direct I.V. application of ozone (as contrasted to the LAHT) in a dosage of at least $0.1 \mathrm{mg} / \mathrm{kg}$ has a unique homeopathic effect that is not observed (and/or has never been described) with the LAHT. When ozone is injected into the bloodstream, it immediately starts to react with any available type of oxidizable substrate, most notably, the lipids of the cell membrane. Lipid peroxidation products of ozone include alkoxyl and peroxyl radicals, polyunsaturated fatty acid (PUFA) hydroxyperoxides, PUFA alcoxyl and peroxyl radicals, singlet oxygen, hydrogen peroxide ("peroxide burst", the mechanism of killing viruses, bacteria and fungi of macrophages, microphages, and blood platelets), ozonides, carbonyls, alkanes and alkenes. If all the different reaction products are taken into consideration, there may be perhaps 10,000 or more different oxidized species in minute ("homeopathic") amounts, formed under conditions of considerable turbulence (simulating homeopathic "succussion", or the vigorous shaking used in classic homeopathy to "potentiate" the effect of the remedy). This brings about a "healing crisis" that simulates milder versions of any hidden but still significant disease processes, that have not been completely resolved, including allergies, old drug toxicities, environmental pollution, old viral, bacterial or fungal infections, even physical traumas, migraines, and other conditions. After the "healing crisis" is brought about by the ozone administration, these conditions are resolved (analogous to the mechanism of action of homeopathic remedies) and people reach a new level of wellbeing that was unattainable before. Particularly impressive is this effect in all chronic allergies, asthma, hay fever, "brain allergies", and in chronic fatigue syndrome, as well as in all types of substance abuse \& addiction including nicotine, alcohol, opiates, cocaine, etc

(7) Direct IV Ozone oxidatively detoxifies any drugs or other toxic substances that have invariably accumulated in the bodies of patients with degenerative disease, especially cancer. This minimizes long-term detrimental effects and prevents late toxicity such as cardiac failure and death from doxorubicin or daunorubicin, permanent sterility from alkylating agents such as cyclophosphamide, melphalan, ifosfamide, etc., pulmonary fibrosis after bleomycin \& nitrosureas such as carmustine \& lomustine, and the myelosuppression seen after vitually all antineoplastic drugs, as well as carcinogenic environmental toxins such as dioxins, paraquat, polycyclic aromatic hydrocarbons, \& other (non-/)halogenated aliphatic/aromatic/polycyclic hydrocarbons found in the air, water, or food taken in.

(8) Hyperthermia effect of direct IV ozone is observed in most patients, especially the ones with extensive tumors and/or significant (concomitant) infections. The effectiveness of hyperthermia or fever in reversing malignancies was known since antiquity. Note that externally induced hyperthermia including immersion of the body in the hot healing waters of balneological cancer resorts, sitting in a sauna [especially, an infrared sauna] or steam bath, was used since antiquity against cancers [=.modern ways] and [Aquasizer baths with ultrapure ozonated water], or simply wrapping oneself in [space] blankets with a hot water bottle. The total body hyperthermia combined with potassium and glucose I.V. was developed in the 1940s by the late Professor Dr. med. Manfred von Ardenne in Dresden, Germany as his very successful low-pH therapy of cancer. This therapy was then superseded by the LSU (now ULS) ENHANCED HIGH-pH THERAPY of CANCER since the mid-1970s. 


\section{APPENDIX II: SUMMARY OF ADVERSE EFFECTS OF CONVENTIONAL CANCER THERAPY}

\section{The "State of the Art" of Conventional Cancer Therapy}

As stated previously in "Cesium and Cancer", "(conventional) [t]reatment modalities of cancer include surgery, radiation and chemotherapy. In those cases where surgery was successful the body's own immune system was able to counteract the reduced amount of tumor tissue. Surgery is likely to produce metastasis without stimulation of the immune system. Radiation may cause damages to the organism, e.g., carcinogenicity of x-rays and other radiations, and their depression of the immune system is well known. Prolonged chemotherapy may cause severe to lethal side effect in some instances, and the use of hormones and interferon are useful only for very few cases of cancer. Conventional treatments of cancer have produced 5-year survival rates which do not reflect the inexorable gradual deterioration of the cancer patients, nor their suffering from various treatment-related adverse reactions, and where chemotherapy of, e.g., breast cancer may shorten the life by 18 to 36 months v. no treatments at all."

Adverse Effects of Cancer Surgery may arise as anesthetic "accidents" and deaths, complications during surgery, \& longterm surgical "aftereffects".

(1) Anesthesia: Over one half of all deaths attributed to anesthesia were caused by excessive blood loss during surgery; the remainder was from aspiration, overdose/misuse of anesthetics, \& faulty technique. Brain damage from anesthesia was attributed in about $50 \%$ to faulty technique. Other longterm effects of anesthesia include lasting immunodepression. (2) Surgery: Besides excessive blood loss and tissue trauma that is often unavoidable even for the most skilled surgeon, cancer surgery, in virtually all cases leads to dissemination of cancer cells and immunodepression. If there is enough immune function, the body may be ably to recognize and eliminate the spread cancer cells. Failure of tumor recognition, most prevalent in blood type $\mathrm{A} \& \mathrm{AB}$, may lead to extensive metastasis.

(3) Longterm Aftereffects: Lung surgery \& massive abdominal resections may leave patients so crippled that they lose their will to live. The same applies to many patients with colostomies, paralysis, or brain damage, and children who suffer an amputation of a limb or other severe mutilations.

Few surgeons are aware of the fact that there is a clinically significant immunodepression after almost any, but especially after (ultra)radical cancer surgery [less prevalent in the U.S. since about 2000](while radiologists are much more aware of the similar one after radiation), and which is manifested by a deficient antibody response to tumor \& other antigens, cellular immunodeficiency with recurrent infections that, if severe, may include opportunistic pathogens, and phagocytic dysfunction (from operative stress) that interferes with removal of (pre)cancerous cells and contributes to bacterial/fungal infections.

Adverse Effects from Radiation include acute radiation syndrome, the hemopoietic, gastrointestinal, \& CNS syndromes, \& pneumonitis \& pericarditis based on the location of the radiation, and late effects.

(1) Acute Radiation Syndrome is characterized by nausea, vomiting, fatigue, loss of appetite \& general malaise that may last for 48 to 72 hours [less prevalent in the U.S., as is (4), since about 2000].

(2) Chest irradiation may cause granulocytopenia \& thrombopenia from bone marrow depression, as well as radiation pneumonitis (insidious onset, cough, dyspnea, cyanosis, \& fever 6-12 weeks after radiotherapy) $\&$ pericarditis.

(3) Abdominal irradiation may cause profuse (\& later chronic) diarrhea (unresponsive to conventional therapy), nausea, vomiting, lymphocyte depression, severe gastrointestinal upset, after a latency of 1 to 2 weeks bloody diarrhea $\&$ hematuria, and fistulas as late complications.

(4) Cranial irradiation may cause after immediate nausea \& vomiting, hypotension, apathy, ataxia, convulsions \& coma, \& delayed necrosis of the brain manifesting as headaches \& a variety of neurological symptoms.

(5) Late Effects: Inductions of secondary cancers of almost all types, as well as of leukemias \& lymphomas, and where the female breast and the thyroid appear to be especially radiosensitive, and immunodepression worse than after surgery [see supra], especially, in addition, chronic depletion of lymphocytes, pancytopenia (especially if the bone marrow had been irradiated), \& severe phagocytic dysfunction.

\section{ADVERSE EFFECTS FROM CHEMOTHERAPY}

Of the about 75 presently used "anti-cancer" drugs, NONE has been proven effective, singly or in combinations, in properly controlled, let alone, double blind, clinical trials. On the contrary, since about 1975 to the present [2004], careful analysis of the results of cancer chemotherapy by Arlin J. Brown proved that these anti-cancer drugs are the MAJOR CAUSE of DEATH of cancer patients. Adverse effects of these drugs not only caused a severe life quality deterioration but also, in most cases, actually SHORTENED the life expectancy as compared to matched untreated controls. The following gives some ideas about acute \& delayed toxicity of these drugs, \& where dose-limiting toxicity is listed in bold. Note that 35 pages, mostly tables, in "Ellenhorn's Medical Toxicology", 2d ed., Williams \& Wilkins, Baltimore, 1997, are devoted to "Cancer Chemotherapeutic Agents/Cytotoxic Drugs".

(a) Acute Toxicity:

Nausea \& vomiting is found with almost all, except, perhaps, with aminoglutethimide, cladribine, $\mathrm{GaNO}_{3}$, gemcitabine, goserelin, the interferons, leuprolide, paxclitacel, tretinoin, \& vincristine, \& which is dose-limiting, e.g., with mechlorethamine (nitrogen mustard).

Anaphylaxis \& other allergic reactions (A\&A) may be encountered with many oft these drugs, e.g., amsocrine, asparaginase \& pegaspargase, bleomycin, cisplatin, cytarabine (\& acute respiratory distress), dacarbacine, dactinomycin, daunorubicin \& doxorubicin, etoposide, fluorouracil (5-FU), methotrexate, paxclitel, etc.

Aldesleukin (IL-2): in addition (+), causes fever; fluid retention; hypotension; respiratory distress; rash, anemia, thrombopenia; diarrhea; erythema nodosum; neutrophil chemotactic defects, etc.

Daunorubicin \& doxorubicin: (+), extravasation necrosis (EVN); acute cardiac toxicity (hours to days after) with EKG- changes including supraventricular arrhythmias, heart block, \& ventricular tachycardia, major drop in ejection fraction, congestive heart failure (CHF), pericardial effusions (myocarditis-pericardiditis syndrome), GI toxicity, etc.

Ifosfamide: (+), cardiac toxicity; nephrotoxicity; confusion; metabolic acidosis \& renal (de Toni-)Fanconi syndrome (proximal renal tubule dysfynction with hyperaminoaciduria, glycosuria, hyperphosphaturia, bicarbonate \& water loss), etc.

Methotrexate: $(+)$ hepatic necrosis; fever; diarrhea, etc.

Paclitaxel: A\&A, dyspnea, hypotension, angioedema, urticaria, etc. Asparaginase \& pegaspargase: A\&A, hypersensitivity; fever, chills; headache; abdominal pain; hyperglycemia leading to coma,etc.

Tretinoin: headache; xerosis; "retinoic acid syndrome" (i.e., fever, dyspnea, pulmonary infiltrates, pleural effusions, peripheral edema, hypotension); arthralgias, myalgias, etc.

(b) Delayed Toxicity: Almost all nonhormonal anticancer drugs show dose-limiting (1) bone marrow depression or (2) delayed leukopenia \& thrombopenia [the latter especially in carmustine, chlorozotocin, lomustine, et al.], as well as cutaneous reactions (sometimes severe), hyperpigmentation, \& ocular toxicity, alopecia (which causes significant patient distress especially in women), \& PERMANENT sterility after alkylating agents, e.g., cyclophosphamide, ifosphamide, \& melphalan. Other dose-limiting toxicities include:

(3) Pneumonitis \& pulmonary fibrosis : bleomycin, busulfan, methotrexate, carmustine \& lomustine, etc.

(4) Renal damage: cisplatin, streptozocin, etc.

(5) Stomatitis \& oral ulcerations: dactinomycin, etc.; both oral \& GI ulcerations: floxuridine, fluorouracil (5-FU), methotrexate, etc.

(6) Cardiotoxicity (cumulative, dose-dependent cardiomyopathy/CHF; may be delayed for years): dauno- $\&$ doxorubicin, etc.

(7) Hypophosphatemia: $\mathrm{GaNO}_{3}$

(8) Hemorrhagic cystitis: ifosfamide, less in cyclophosphamide, etc

(9) Teratogenicity; cheilitis: isotretinoin ${ }^{1^{*}} \&$ tretinoin $^{2^{*}} ; \&$ where ${ }^{1^{*}} \&^{2^{*}}$ cause rashes; pseudotumor cerebri; hypertriglyceridemia, $\&^{1^{*}},(+)$, causes anorexia; xerostomia, xerophthalmia \& conjunctivitis; bone $\&$ joint pain $\&^{2^{*}},(+)$, causes thrombophlebitis; \& leukocytosis; whereas acute toxicity of vit. A (retinol \& retinyl esters) can be almost completely avoided (up to $3 \mathrm{MU} /$ day x 30 days) with concomitant vit. E (e.g., mixed tocopherols).

(10) CNS depression: mitotane

(11) Hemorrhagic diathesis: plicamycin

(12) Peripheral neuropathy: vincristine

(13) Mucositis: dauno- \& doxorubicin, trimetrexate 


\section{APPENDIX III: DIETARY CARCINOGENS}

\section{A. NATURALLY OCCURRING DIETARY CARCINOGENS} pesticides"(protecting plants against fungi, insects, \& animal predators) or formed in the stomach from nitrites \& amines in the diet. Acrolein, a mycotoxins (metabolites produced by molds in food).

(a) Natural Pesticides have been found carcinogenic if given in high discussed in "Nutrients in Cancer", supra [p. 9].

doses to animals though there is no evidence of carcinogenicity in (a) Heterocyclic Aromatic Amines (HAAs)

humans; allyl isothiocyanate ; in cabbage, cauliflower, Brussels sprouts, HAAs are potent mutagens \& animal carcinogens causing cancers of the mustard, \& horseradish is, in fact, clearly anti-carcinogenic. There is no liver, colon, mammary gland, skin, prostate, lymphoid tissue, oral cavity, evidence for human carcinogenicity of caffeic acid occurs in apples, lung, etc. Of 20-some HAAs, 4 are possible human carcinogens, including pears, cherries, carrots, celery, lettuce, potatoes, endive, grapes, eggplant, 2 amino 3 methylimidazo [4,5-f] quinoline (IQ); 2 amino 3,4 thyme, basil, dill, caraway, rosemary, tarragon, \& coffee beans,; of safrole dimethylimidazo[4,5-f]quinoline (MeIQ); 2-amino-3,8-dimethylimidazo in nutmeg, mace, pepper, cinnamon, natural root beer; estragole in basil, [4,5-f] quinoxaline (8-MeIQx); and 2 amino 1 methyl 6 fennel, \& tarragon; carvacrol in marjoram; furocoumarins in lime, citrus phenylimidazo[4.5-b] pyridine (PhIP). HAA-DNA form major adducts oils, carrots, celery, parsley, \& parsnips; nor of pyrrolizidines in comfrey with C8, \& IQ \& MeIQx form minor adducts at N2 of guanine, and where tea. The hepatic carcinogenicity of hydrazine, in mushrooms is linked to the metabolic activation appear to occur via N-oxidation \& O- acetylation the hypo-methylation of organ DNA that occurs only in folic acid to form N-acetoxy arylamines that bind to DNA, \& where rapid oxidizers deficiency. Note though that hydrazine overdosage (if used as "anticancer \& acetylators may be at geater cancer risk.

agent") leads to ataxia, lateral nystagmus, loss of vibration sense, \& (b) Polycyclic Aromatic Hydrocarbons (PAHs), particularly benzo[a]seizures, \& it is also hepatotoxic. (AFB1) \& natural mixtures of aflatoxins (B1, B2 G1, M1, M2 etc \& adducts \& ras oncogene mutations \& that the $h$ GSTPI which are also mutagenic, teratogenic, \& immunodepressive), as well as factor in susceptibility to PAH-related cancers.

sterigmatocystin, while griseofulvin (antifungal) is moderately CAgenic. (c) N-Nitroso Compounds (NOCs) are carcinogenic in animals, including Fumonisins and ochratoxin A are possible human carcinogens. Citrinin, primates, after oral ingestion. They may be a significant risk factor for patulin, penicillic acid, \& zearalenone are carcinogenic for animals. human cancers of the stomach, esophagus, colon \& rectum, nasopharynx, (1) Aflatoxins, produced by Aspergillus parasiticus \& A. flavus, occur in urinary tract, \& liver. Note that ascorbic acid, tocopherols, peanuts, maize, cotton seed, rye, barley, food grains, etc. Fowl \& other retinoids,phenolic \& sulfhydryl compounds, orange peel, and \& other farm animals fed infected ground nut meal may die of aflatoxicosis. nutrients \& specific foods mentioned in "Nutrients and Cancer", supra, Aflatoxins cause liver \& gallbladder cancers, \& may increase lung cancer may inhibit the formation of endogenous NOCs.

incidence via the AFB1-2,3-epoxide that forms the AFB1-N7-Gua adduct

with the guanine of the DNA (which is also transferred transplacentally C. SYNTHETIC DIETARY CARCINOGEN (see also p.599 of "Cancer", suggesting initiation of hepatocellular carcinoma in utero). Aflatoxins also 6th ed., by DeVita, Hellman, \& Rosenberg, Lippincott, Philadelphia, 2002]

cause cirrhosis of the liver, including Indian childhood cirrhosis, acute (a) Direct/Intentional Synthetic Additives include i.a., antioxidants, hepatic failure \& encephalopathy, Reye syndrome (acute severe colorants, flavor ingredients, artificial sweeteners, solvents, \& humectants. encephalopathy with hepatic dysfunction in children after viral infection (b) Indirect/Unintentional Synthetic Additives include pesticides, (influenza/varicella virus) treated with aspirin; also recurrent vomiting, solvents, and packaging-derived chemicals. These chemicals, which elevated transaminases \& ammonia, prolonged prothrombin time, fatty number more than 2000, enter the food supply during production, hepatomegaly; fever, diarrhea, abdominal pain, anorexia; followed by processing, packaging, and storage from a variety of sources. Of these, encephalopathy with acute brain swelling, coma within 24 - 48 hours, PESTICIDES are of major concern since most, if not all, pesticides have seizures, decerebrate rigidity \&, eventually, death from acute hepatic \& human toxicity potential, including carcinogenicity. Of these, arsenicals, renal failure), \& kwashiorkor (where aflatoxins contribute to etiology, benzal chloride, \& fluoride insecticides are highly carcinogenic, while increase childhood susceptibility to infections/parasitosis \& cancers, amitrole, benzotrichloride, carbon tetrachloride, chlorophenols, p-diretarded growth chronic diarrhea, anemia, hypalbuminemia, etc. primarily chlorobenzene, ethylene dibromide \& thiourea, formaldehyde, phenoxy from protein, et al., malnutrition). Note that aflatoxin-contaminated heroin acids, 2,3,7,8-tetrachlorodibenzo-p-dioxin, \& 2,4,6-trichlorophenol are may contribute to the suppression of cell-mediated immunity (i.e., moderately CAgenic in humans, and where, because of bioaccumulation, resulting from activation of T- lymphocytes) seen in AIDS patients.

(2) Sterigmatocystin, from A. versicolor/flavus/ruber/luteum in wheat, peanuts, and rice, is highly carcinogenic in animals.

(3) Fumosinins (esp. B1), in maize, are carcinogenic in rodents (liver \& kidney cancers) \& have been linked to esophageal cancer in humans.

(4) Ochratoxin, from A. ochraceus, P. veridatum/cyclopium in wheat, oats, rice, \& green coffee beans, has been implicated in renal adenomas \& Balkan nephropathy. Zearalenone, from Fusarium spp. in maize, wheat, sorghum, \& feed several phthalate ester plasticizers (especially DEHP \& its metabolite grains, has been implicated in cervical cancer \& premature thelarche.

the cancer \& other longterm health risks from pesticides increase with repeated exposure over many years.[50 pages in "Ellenhorn's Medical Toxicology",2d ed., 1997, deal with "Pesticides"]. Note that the most effective insecticide, DDT (p,p'-dichlorodiphenyltrichloroethane, now: chlorphenotane), is anticarcinogenic \& (properly used) virtually non-toxic to humans. Its ban in 1972, since it almost eradicated Anopheles spp., caused excess deaths from malaria alone of $>90$ million people by 2004. Of packaging materials, vinyl chloride, is a human carcinogen, and MEHP), are potential carcinogens. Note that extensive use of DEHP(6) T-2 toxin, in barley, maize, safflower seeds, \& cereals, may contribute plasticized PVC blood tubing caused necrotizing dermatitis \& plasticizerto pellagra (primarily caused by failure to convert tryptophan to niacin or induced hepatitis, \& testicular atrophy with sterility in dialysis patients, \& niacin deficiency \& characterized by dermatitis, mucositis, diarrhea, \& inhalation of DEHP \& MEHP causes bronchial asthma; NBBS (in plastic psychic disturbances including depression, irritability, anxiety, confusion, resins \& fungicides) may pose risk of amyotrophic lateral sclerosis, disorientation, delusions, \& hallucinations).

\section{B. PRODUCTS of FOOD PREPARATION \& PROCESSING} Food preparation \&preservation are major sources of dietary carcinogens, industrial solvents trichloro-ethane \& -ethylene, tetra- \& 1,2 dichloroincluding heterocyclic aromatic amines (HAAs), formed during frying, ethylene, as well as arsenic \& asbestos, and pesticides in wellwater are broiling, \& grilling of high-protein foods and more prevalent in well- major public health concerns. Fluoride is a carcinogen, is THE aging done meats; polycyclic aromatic hydrocarbons (PAHs), formed during factor, $>1 \mathrm{ppm}$ in drinking water increases risk of osteoporotic hip broiling \& smoking food, paticularly ground beef and steaks, less in pork fracture, \& ingestion of $>10 \mathrm{mg} / \mathrm{kg}^{-}$of $\mathrm{F}^{-}$(in toothpaste) may be lethal. 


\section{APPENDIX IV: LIST OF CESIUM \& RUBIDIUM ARTICLES that appeared in Pharmacology, Biochemistry \& Behavior, Vol. 21, Suppl. I, 1984 Alkali Metals: An Update. Pharmacol Biochem Behav. 1984; 21 Suppl 1:1-135.}

1: Brewer AK.

The high $\mathrm{pH}$ therapy for cancer tests on mice and humans

Pharmacol Biochem Behav. 1984; 21 Suppl 1: 1-5.

2: Sartori HE.

Nutrients and cancer: an introduction to cesium therapy. Pharmacol

Biochem Behav. 1984; 21 Suppl 1: 7-10.

3: Sartori HE.

Cesium therapy in cancer patients.

Pharmacol Biochem Behav. 1984; 21 Suppl 1: 11-3.

4: Neulieb R.

Effect of oral intake of cesium chloride: a single case report.

Pharmacol Biochem Behav. 1984; 21 Suppl 1: 15-6.

5: Pinsky C, Bose R.

Pharmacological and toxicological investigations of cesium.

Pharmacol Biochem Behav. 1984; 21 Suppl 1: 17-23.

6: Tufte MJ, Tufte FW, Brewer AK.

The response of colon carcinoma in mice to cesium, zinc and vitamin A.

Pharmacol Biochem Behav. 1984; 21 Suppl 1: 25-6.

7: Messiha FS.

Biochemical aspects of cesium administration in tumor-bearing mice. Pharmacol Biochem Behav. 1984; 21 Suppl 1: 27-30.

8: Messiha FS, Stocco DM.

Effect of cesium and potassium salts on survival of rats bearing Novikoff hepatoma.

Pharmacol Biochem Behav. 1984; 21 Suppl 1: 31-4.

9: Messiha FS.

Effect of cesium and ethanol on tumor bearing rats.

Pharmacol Biochem Behav. 1984; 21 Suppl 1: 35-40

10: Yung CY.

A synopsis on metals in medicine and psychiatry.

Pharmacol Biochem Behav. 1984; 21 Suppl 1: 41-7.

11: Malek-Ahmadi P, Williams JA.

Rubidium in psychiatry: research implications.

Pharmacol Biochem Behav. 1984; 21 Suppl 1: 49-50.

12: Yung CY.

A review of clinical trials of lithium in medicine.

Pharmacol Biochem Behav. 1984; 21 Suppl 1: 51-5. Review.

13: Yung CY.

A review of clinical trials of lithium in neurology.

Pharmacol Biochem Behav. 1984; 21 Suppl 1: 57-64. Review.
15: Yung CY.

Neuropsychiatric manifestations of alkali metal deficiency and excess. Pharmacol Biochem Behav. 1984; 21 Suppl 1: 71-5. Review.

16: Pannell KH, La Neave CK, Rico E, Arkles B.

Concerning the relative non-toxicity of silacrown ionophores.

Pharmacol Biochem Behav. 1984; 21 Suppl 1: 77-80.

17: Roberts LA.

Chronotropic effect of alkali metals on spontaneously beating

right atria.

Pharmacol Biochem Behav. 1984; 21 Suppl 1: 81-5.

18: Messiha FS.

Lithium, rubidium and cesium: cerebral pharmacokinetics and alcohol interactions.

Pharmacol Biochem Behav. 1984; 21 Suppl. 1: 87-92.

19: Messiha FS, McGrath J.

Modulation of nitrogen dioxide toxicity by lithium.

Pharmacol Biochem Behav. 1984; 21 Suppl 1: 93-7.

20: McGrath JJ.

The effects of carbon monoxide on the heart: an in vitro study.

Pharmacol Biochem Behav. 1984; 21 Suppl 1: 99-102.

21: McGrath JJ, Leviseur C.

Cardiorespiratory responses to intestinal injection of carbon monoxide. Pharmacol Biochem Behav. 1984; 21 Suppl 1: 103-7.

22: Baudhuin MG, Jefferson JW, Greist JH.

The Lithium Information Center: an efficient information service.

Pharmacol Biochem Behav. 1984; 21 Suppl 1: 109-11.

23: Messiha FS.

Cesium: a bibliography update.

Pharmacol Biochem Behav. 1984; 21 Suppl 1: 113-29.

14: Paragas MG.

Lithium adverse reactions in psychiatric patients.

Pharmacol Biochem Behav. 1984; 21 Suppl 1: 65-9. Review. 